\title{
1 Phototroph-heterotroph interactions during growth and long-term 2 starvation across Prochlorococcus and Alteromonas diversity
}

3

4 Osnat Weissberg*, Dikla Aharonovich* and Daniel Sher

5 Department of Marine Biology, Leon H. Charney School of Marine Sciences, University of Haifa, 6 Israel

$7 \quad *$ Dikla Aharonovich and Osnat Weissberg contributed equally to this study

8 Correspondence: $\underline{\text { dsher@univ.haifa.ac.il }}$

Running title: Prochlorococcus-Alteromonas interactions across diversity

\begin{abstract}
Interactions among microorganisms are ubiquitous, yet to what extent strain-level diversity affects interactions is unclear. Phototroph-heterotroph interactions in marine environments have been studied intensively, due to their potential impact on ocean ecosystems and biogeochemistry. Here, we characterize the interactions between five strains each of two globally abundant marine bacteria, Prochlorococcus (a phototroph) and Alteromonas (a heterotroph), from the first encounter between individual strains and over more than a year of subsequent coculturing. Prochlorococcus-Alteromonas interactions affected primarily the dynamics of culture decline, which we interpret as representing cell mortality and lysis. The shape of the decline curve and the carrying capacity of the co-cultures were determined by the phototroph and not the heterotroph strains involved. Comparing various models of culture mortality suggests that death rate increases over time in mono-cultures but decreases in co-cultures, with cells potentially becoming more resistant to stress. During 435 days of co-culture, mutations accumulated in one Prochlorococcus strain (MIT9313) in genes involved in nitrogen metabolism and the stringent response, indicating that these processes occur during long-term nitrogen starvation. Our results suggest potential mechanisms involved in long-term starvation survival in co-culture, and highlight the information-rich growth and death curves as a useful readout of the interaction phenotype.
\end{abstract}

Keywords: Microbial interactions, growth curves, machine learning, mortality, co-culture 


\section{Introduction}

36 Interactions among microorganisms occur in every known ecosystem. Positive (synergistic) interactions allow organisms to exchange resources, potentially increasing biodiversity, whereas negative interactions such as competition, allelopathy and predation may lead to organisms displacing one another (recently reviewed by (Fritts et al., 2021; Gralka et al., 2020)). Detailed studies of the interactions between selected model organisms (often in laboratory co-cultures) have begun to reveal the diversity of molecular mechanisms whereby organisms interact with each other (Fritts et al., 2021; Harrington et al., 2021; Weisskopf et al., 2021). However, it is currently unknown to what extent the studied interactions are conserved across organisms, growth stages or environmental conditions. For example, while broad-scale phylogenetic patterns are often observed in microbial interactions, closely related bacteria may differ in the way they interact with other organisms, likely as a result of the significant genetic diversity observed in many microbial clades (e.g. (Cordero et al., 2012; Long \& Azam, 2001)). Additionally, the same pair of interacting organisms can synergize or compete depending on the composition of the culture media and the growth stage of (co)-culture (e.g. (Grossart \& Simon, 2007; Segev et al., 2016; Seyedsayamdost et al., 2011). Finally, both the coarse-grained ecological classification of microbial interactions (e.g. positive/negative) and the high-resolution mechanistic view obtained using advanced physiology and omics approaches are difficult to translate into quantitative, predictive models of organismal growth and decline (Antoniewicz, 2020; Gralka et al., 2020; Zoccarato et al., 2020). Therefore, we still face fundamental challenges in interpreting and understanding the increasingly diverse and mechanistic view of microbial interactions and translating these insights into conceptual and mathematical models of cell growth and death.

Growth curves from batch (co)-cultures are information-rich views of microbial growth and mortality, which can provide an important link between the phenotypic outcome of microbial interactions and the underlying mechanism. Growth curves can be divided into discrete phases (lag, exponential, stationary, decline and long-term stationary phases), and can be used to extract quantitative parameters such as growth rates, lag times, etc. (Sher et al., 2011; Warringer et al., 2008). An extra layer of more subtle information may exist in the shapes of the growth curves, providing hints of important shifts in the physiology of the growing organisms, as classically demonstrated for diauxic growth in E. coli (Monod, 1949). Notably, while many studies of bacterial interactions focus on the exponential growth stage or on culture yield at a specific timepoint (e.g. (Foster \& Bell, 2012; Pacheco et al., 2021; Vetsigian et al., 2011)), fewer studies look at the shape and dynamics of the decline phases, which can provide important hints regarding the effect of interactions on the process of microbial mortality (e.g. (Christie-Oleza et al., 2017; Grossart, 1999; Ratzke \& Gore, 2017)).

Here, we explore to what extent intra-clade diversity affects the outcome of microbial interactions, using growth curves as the major phenotypic "readout". Our model organisms are two globally abundant clades of marine bacteria: a cyanobacterial primary producer (Prochlorococcus) and a heterotrophic $\gamma$-proteobacterium (Alteromonas). Interactions between marine phototrophs (phytoplankton, including cyanobacteria) and heterotrophic bacteria have been studied intensively, as phytoplankton are responsible for about one-half of the 
al., 2016; Seymour et al., 2017)). Thus, phytoplankton-bacteria interactions may strongly affect community structure and function on scales from microns to thousands of kilometers (Hennon et al., 2018; J. Jeffrey Morris et al., 2012). Our model primary producer, Prochlorococcus, is found throughout the euphotic zone, the sunlit upper portion of the ocean. There are multiple Prochlorococcus clades, broadly partitioned into high-light (HL) and low light (LL) adapted ecotypes, which differ in their photosynthetic parameters and occupy different niches in the ocean (surface vs deep water, reviewed by (Biller et al., 2015)). Strains differ also in traits such as the capacity to utilize different forms of inorganic nutrients and organic matter, as well as in their interactions with heterotrophic bacteria and phage. Alteromonas is a clade of free-living marine bacteria, which are also partitioned into surface and deep groups ( $A$. macleodii and $A$. mediterranea, respectively) (López-Pérez \& Rodriguez-Valera, 2016). Alteromonas strains also exhibit diverse capabilities to utilize carbohydrates, acquire iron and in motility (Koch et al., 2020). Interactions between individual strains of Prochlorococcus and Alteromonas have been characterized in some detail (Aharonovich \& Sher, 2016; Diner et al., 2016; Hennon et al., 2018; Hou et al., 2018; J. J. Morris et al., 2011; Roth-Rosenberg et al., 2020; Sher et al., 2011). While the phenotype and gene expression patterns during interactions vary between strains, this variability has not been explored systematically (Aharonovich \& Sher, 2016; Biller et al., 2016; Sher et al., 2011). Notably, strain- and condition-dependent phytoplankton-heterotroph interactions are observed also in other systems, including Synechococcus, a close relative of Prochlorococcus (Christie-Oleza et al., 2017; Zheng et al., 2020), as well as eukaryotic microalgae (e.g. coccolithophores and diatoms, (Amin et al., 2015; Grossart \& Simon, 2007; Segev et al., 2016; Seyedsayamdost et al., 2011)).

We characterized the interactions between five strains each of Prochlorococcus and Alteromonas, from the first encounter between previously-axenic strains (i.e., grown in mono-culture) and over up to 435 days of co-culture ( 25 phototroph-heterotroph combinations across $\sim 1.2$ years, Fig $1 \mathrm{a}$, Fig S1). The culturing period spanned multiple cycles of exponential growth, culture decline and long-term nitrogen starvation (Roth-Rosenberg et al., 2020). Nitrogen stress or starvation occurs across wide swaths of the global ocean, and affects a significant fraction of the Prochlorococcus diversity (Saito et al., 2014; Ustick et al., 2021). We focused our analysis on Prochlorococcus growth and decline, which is easily measured using bulk culture fluorescence in a non-invasive manner (e.g. (Coe et al., 2016; Sher et al., 2011). Using this dataset of 429 growth curves, as well as associated cell number measurements and genome resequencing, we ask: i) How do the interactions between Prochlorococcus and Alteromonas vary across the diversity of each organisms? ii) Do the interactions change over time (i.e. do the organisms adapt to "living together")? iii) When, during the life-cycle of a Prochlorococcus batch culture, do microbial interactions have the largest impact on growth and death, and can this impact be quantified? iv) Can the combination of growth curves, cell counts and genomic data provide hints as to which potential metabolic pathways are affected by the long-term interactions? 


\section{Results and Discussion}

\section{Differences in co-culture phenotype are related to Prochlorococcus but not 120 Alteromonas strains}

121 The axenic cultures and the co-cultures differed primarily in their decline stage, and this was 122 observed already from the first encounter between previously-axenic Prochlorococcus and 123 Alteromonas (Experiment 1). In experiment 1, all co-cultures and axenic controls grew 124 exponentially (Fig 1a, b). However, all axenic cultures showed a rapid and mostly monotonic 125 decrease in fluorescence starting shortly after the cultures stopped growing, reaching levels 126 below the limit of detection after $\sim 20-30$ days. In contrast, the decline of co-cultures rapidly 127 slowed, and in some cases was interrupted by an extended "plateau" or second growth stage (Fig 128 1b). Across multiple experiments, 92\% of the co-cultures contained living cells for at least 140 129 days, meaning that they could be revived by transfer into fresh media. In contrast, none of the 130 axenic cultures were able to re-grow when transferred into fresh media after 60 days (Fig 1a, Fig 131 S1). These results are consistent with previous studies of Prochlorococcus (Roth-Rosenberg et al., 132 2020) and Synechococcus (Christie-Oleza et al., 2017). Similarly, it has previously been shown that 133 Prochlorococcus MIT9313 is initially inhibited by co-culture with Alteromonas HOT1A3, while 134 MED4 is not (Aharonovich \& Sher, 2016; Sher et al., 2011). This "delayed growth" phenotype was 135 observed here too, was specific to MIT9313 (not observed in other Prochlorococcus strains) and 136 occurred with all Alteromonas strains tested (Fig 1b). 
bioRxiv preprint doi: https://doi.org/10.1101/2021.10.26.465881; this version posted November 22, 2021. The copyright holder for this preprint (which was not certified by peer review) is the author/funder, who has granted bioRxiv a license to display the preprint in perpetuity. It is made available under aCC-BY-NC-ND 4.0 International license.

\section{a}
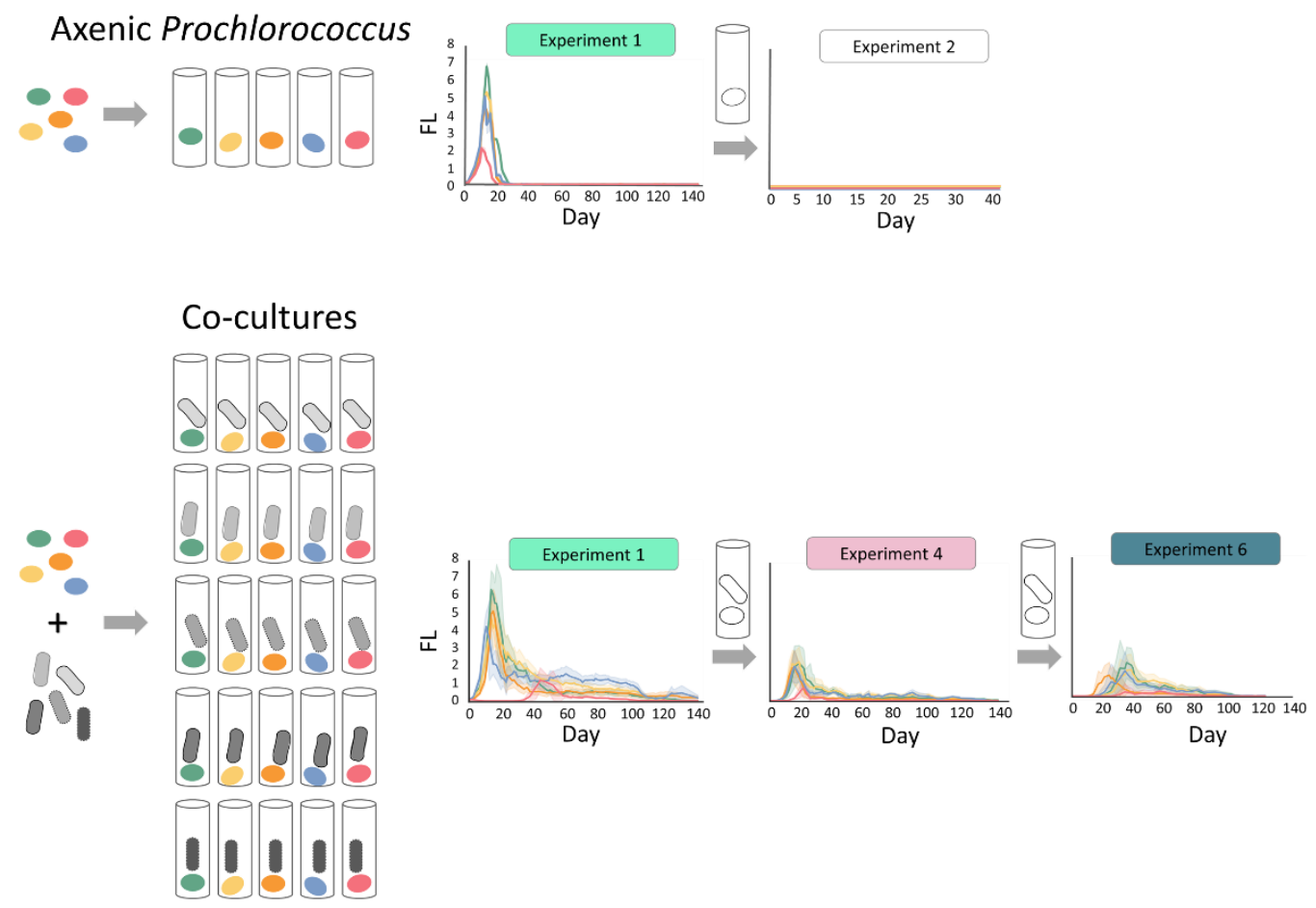

b

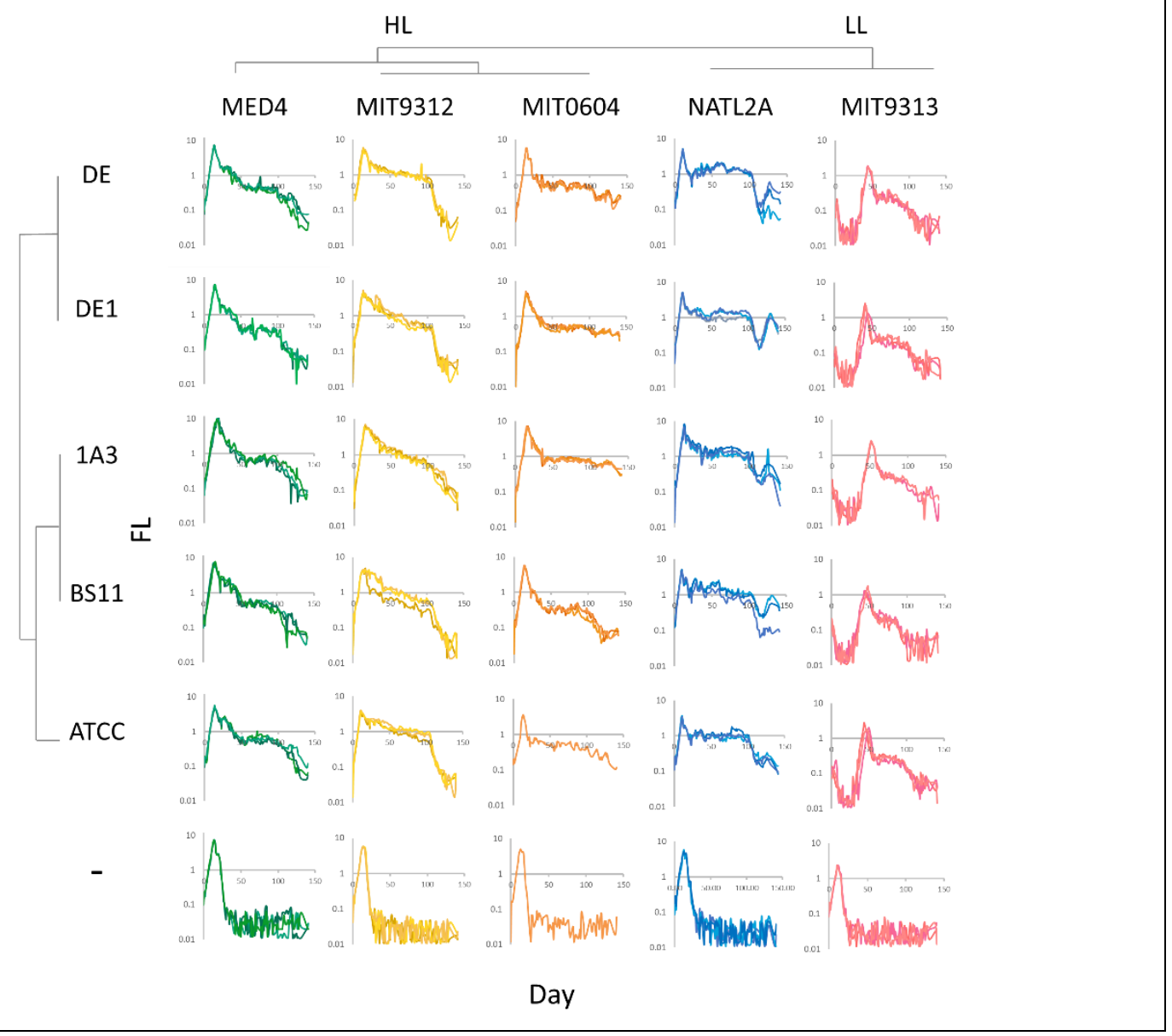


Fig 1: Overview of the dynamics of Prochlorococcus-Alteromonas co-cultures from first encounter and over multiple transfers. a. Mean growth curves of the five Prochlorococcus strains over multiple cycles of exponential growth, culture decline and long-term starvation. The top row shows the transfer of axenic strains from experiment 1 after 60 days, with no subsequent growth observed. The bottom row shows the transfer of co-cultures from experiment 1 after 100 days (experiment 4) and additional transfer after 140 days (experiment 6), with subsequent growth. Shaded areas indicate standard error. b. High reproducibility and strain-specific dynamics of the initial contact between Prochlorococcus and Alteromonas strains (experiment 1). Three biological replicates for each mono-culture and co-culture are shown.

139 A visual inspection of the growth curves in Fig 1b suggested subtle yet consistent differences in 140 the shape of the growth curve, and especially the decline phase, between different 141 Prochlorococcus strains. To test this, we used the growth curves as input for a Principal 142 Component Analysis (PCA), revealing that the growth curves from each Prochlorococcus strain 143 clustered together, regardless of which Alteromonas strain they were co-cultured with (Fig 2). The 144 growth curves of all high-light adapted strains (MED4, MIT9312 and MIT0604) were relatively 145 similar, the low-light I strain NATL2A was somewhat distinct, and the low-light IV strain MIT9313 146 was a clear outlier, consistent with this strain being the only one initially inhibited in all co147 cultures. This strain (MIT9313) stands out even when the impact of growth timing and magnitude 148 was removed by performing the ordination after scaling and aligning the growth times. The 149 survival of Prochlorococcus after extended nitrogen starvation and the clustering of the growth 150 curves by Prochlorococcus but not Alteromonas strains were observed also in multiple subsequent 151 transfers into fresh media, and are thus robust to the time in co-culture and the initial cell 152 densities (Supplementary text S1).

153 MIT9313 belongs to the low-light adapted clade IV (LLIV), which are relatively distant from other 154 Prochlorococcus strains and differ from them in multiple physiological aspects including the 155 structure of their cell wall (Ting et al., 2007), the use of different (and nitrogen-containing) 156 compatible solutes (Klähn et al., 2010) and the production of multiple peptide secondary 157 metabolites (lanthipeptides,(Cubillos-Ruiz et al., 2017; Li et al., 2010)). LLIV cells also have larger 158 genomes, and are predicted to take up a higher diversity of organic compounds such as sugars 159 and amino acids (Yelton et al., 2016). It is intriguing that this strain, which has higher predicted 160 metabolic and regulatory flexibilities (Kettler et al., 2007), differs from all other Prochlorococcus 161 strains in the phenotype of co-culture and is the only one initially inhibited in co-culture with 162 Alteromonas. 

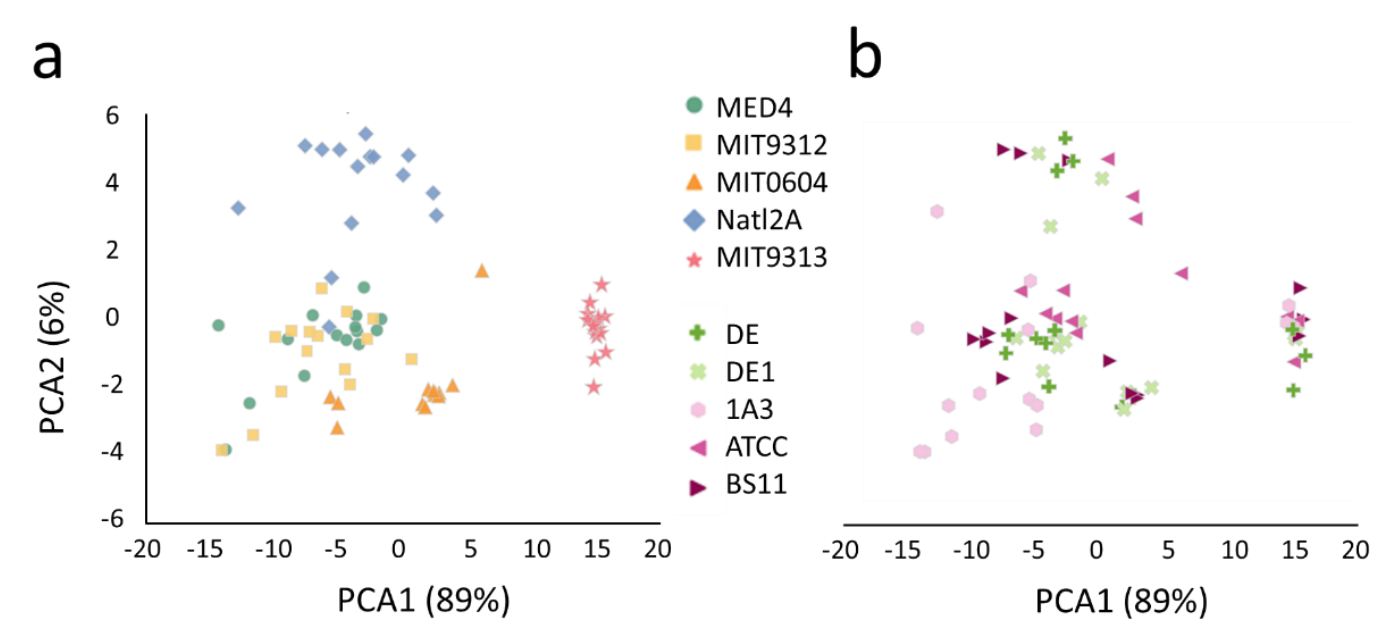

Fig 2: Principal component analysis (PCA) of the growth curves from all co-cultures during 140 days of experiment 1. The ordination is colored by Prochlorococcus ( $\mathrm{a}$ ) and by Alteromonas (b) strains. The growth curves cluster by Prochlorococcus strain (Adonis test, $F(4,68)=80.425, p=$ 0.001 ) and not by Alteromonas strain (Adonis test, $F(4,68)=1.69, p=0.17$ )

The differences between Prochlorococcus strains are most evident in the decline and long-term starvation stages

We next used Random Forest Classification to quantitatively determine which stages of the coculture were most different between the Prochlorococcus-Alteromonas pairs. The algorithm accurately predicted, from the growth curves, the Prochlorococcus strain (10x cross validation accuracy $0.92 \pm 0.17$ ). However, it performed much more poorly when trying to predict the Alteromonas strain (accuracy $0.62 \pm 0.58$ ) (Fig S4a), providing further support to the observation from the PCA in Fig 2 that the shape of the growth and decline curves was driven by the specific Prochlorococcus strain and not by the Alteromonas. The classification of the Prochlorococcus strains relied heavily on days during the decline phase, as these times had the highest Random Forest feature importance, in agreement with the visual inspection of the growth curves (Fig S4b). Similar results were obtained in all subsequent transfers (Supplementary text S1, Fig S4a).

Focusing on the decline stage, we asked whether the differences in growth curves during longterm co-culture represent differences in the number of cells. This is because physiological differences such as in the amount of chlorophyll per cell, or the fraction of chlorotic Prochlorococcus cells, could also affect the growth curves (Coe et al., 2016; Roth-Rosenberg et al., 2020). Flow cytometry counts during the decline stage (after 60, 100 and 140 days) revealed a decrease in the number of Prochlorococcus cells over time (Fig 3a), yet the number of cells in the co-cultures was still 3-4 orders of magnitude higher than in the axenic cultures (Fig S5). This is consistent with the growth curves (Fig 1). The number of Alteromonas cells also declined with time in the co-cultures (Fig 3a), but the difference between the axenic cultures and the co-cultures was much less pronounced than in Prochlorococcus (up to 4-5-fold after 100 days, Fig S5c). This may be due to the ability of Alteromonas to utilize the organic carbon from the natural-seawater- 
189 based media, in addition to the dissolved organic matter (DOM) produced by Prochlorococcus

190 (Pedler et al., 2014).

191 We next asked whether the carrying capacity of the long-term co-cultures, defined as the sum of 192 the concentrations of Prochlorococcus and Alteromonas cells, depends on the Prochlorococcus or 193 the Alteromonas strain. Put differently, one could hypothesize that the total number of cells (and 194 hence the carrying capacity) of the co-culture could depend on the photosynthetically-fixed C 195 provided by Prochlorococcus, or alternatively on the recycling capacity of the different 196 Alteromonas strains. As shown in Fig $3 \mathrm{~b}$ and 3c, on days 60 and 100, the number of both 197 Prochlorococcus and Alteromonas cells clustered depending on the Prochlorococcus strain 198 (Adonis, $\mathrm{p}=0.001$ ), but not on the Alteromonas strain (Adonis, $\mathrm{p}>0.05$ ). In terms of carrying 199 capacity, there are clear differences between Prochlorococcus strains (Fig S6a), but not 200 Alteromonas strains (Fig S6b). Interestingly, two of the Prochlorococcus strains, MIT9312 and 201 MIT9313 have similar (and lower) carrying capacity. These two strains belong to different 202 ecotypes but were isolated from the same drop of water. Taken together, these results suggest 203 that it is the dynamics of the Prochlorococcus strains, including potentially the amount or 204 composition of fixed and released organic C, which determine the total community carrying 205 capacity.

206 By day 140, the cell numbers had declined significantly, and there was no longer a correlation 207 between the number of Prochlorococcus and Alteromonas cells (Fig 3). This suggests that the 208 system is not in steady state, with a slow yet constant reduction in carrying capacity evident by 209 the decrease in cell numbers. Indeed, the co-cultures did not survive indefinitely - in a subsequent 210 experiment, only 16/30 cultures could be transferred after 195 days (Fig S7a, b), and only 3/75 211 cultures could be transferred after 250 days (Fig S7c). Notably, MIT0604 was the strain most likely 212 to survive transfer after these extended periods, and was also the most abundant strain after 140 213 days (Fig $3 b$ ). While we do not currently have an explanation for the higher survival of this strain, 214 it is noteworthy that it is the only strain to utilize nitrate (Hackl et al., 2021). 


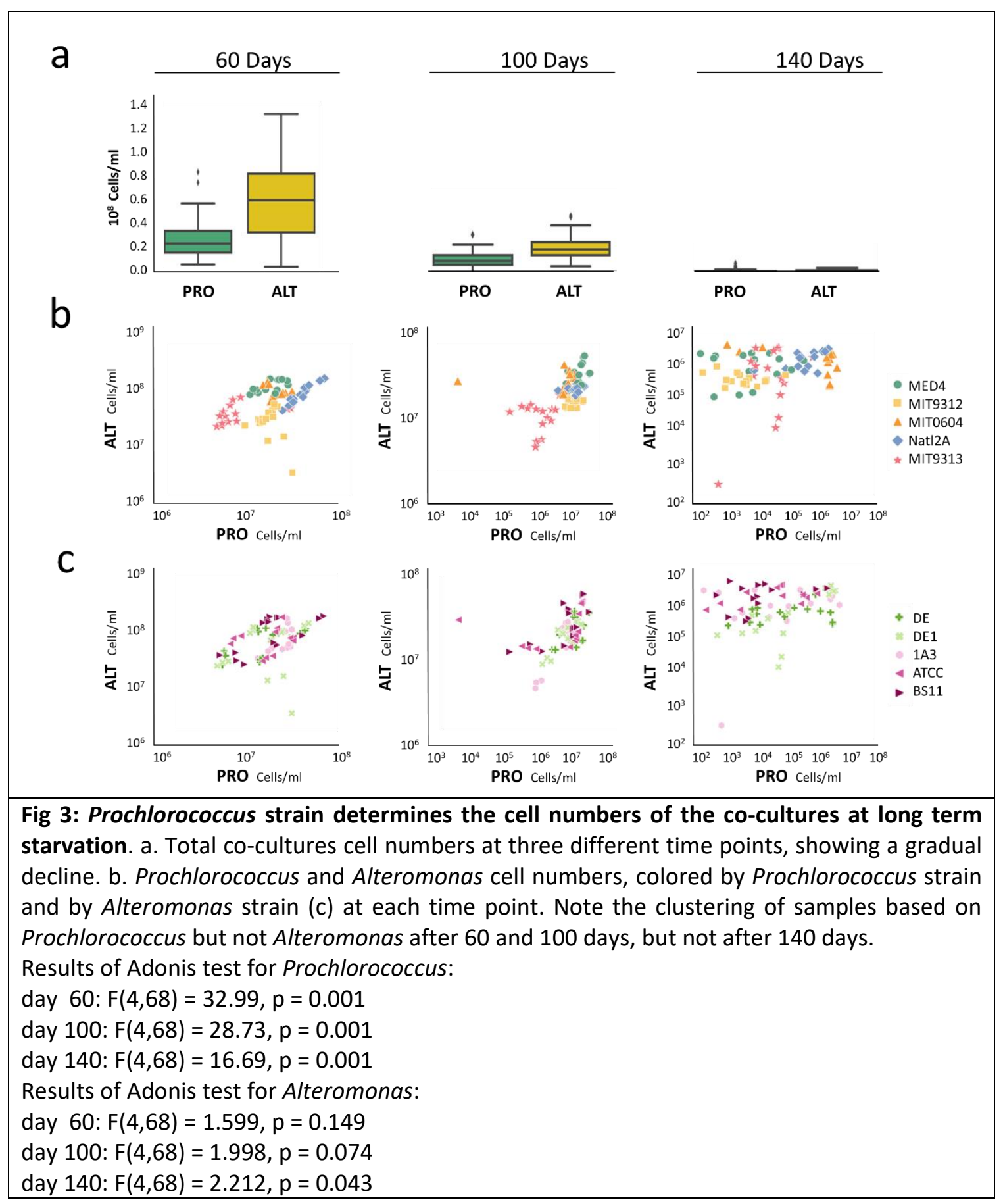

218 Given that the most striking effect of co-culture was on the decline phase of the co-cultures, we asked whether we could quantify this effect, and whether we could identify an appropriate model for mathematically describing culture decline. Importantly, while the growth of bacteria has been extensively studied and modelled, the decline of bacterial cultures, representing bacterial 
222 mortality, is much less studied, and mortality is rarely represented in ecological or biogeochemical 223 models of microbial dynamics (Shoemaker et al., 2021). Bacterial mortality has, however, often 224 been modelled in the context of food safety and genome evolution, using either mechanistic or 225 descriptive approaches (Brouwer et al., 2017; Crane \& Moore, 1986; Finkel \& Kolter, 1999; Patra 226 \& Klumpp, 2013; Shoemaker et al., 2021) We chose to focus on four previously-described models 227 which are relatively simple and have a clear biological interpretation (Fig 4a, Table 1). The 228 Exponential model is the simplest and most commonly used one (Pruitt \& Kamau, 1993). The Bi229 exponential model is slightly more complex, representing two separate subpopulations in the 230 community, each with its own death rate (Crane \& Moore, 1986). Weibull model is a probabilistic 231 model, modeling heterogeneous population with a diverse stress tolerance (Shoemaker et al., 232 2021; Van Boekel, 2002) and finally the Harmonic model employs a quadratic rate of decline which 233 is often associated with predator-prey interaction or encounter rate (Pruitt \& Kamau, 1993). 234 When fitting each of these models to the decline phase of the growth curves, the Weibull model 235 stands out as it has a low error for both axenic and co-cultures (Table 1, Fig 4b). Based on this 236 model, and assuming that culture fluorescence is related to the number of non-lysed cells in the media, axenic Prochlorococcus cells die more than ten-fold faster than cells in co-culture (2238 decimal reduction time, $\mathrm{td}_{2}$, is $12.58 \pm 3.85$ days for axenic cultures and $316 \pm 337$ days for co239 cultures). 
242 Table 1: Mathematical description and biological interpretation of four models used to describe

243 bacterial mortality

\begin{tabular}{|c|c|c|c|c|c|c|}
\hline $\begin{array}{l}\text { Mathematical } \\
\text { model }\end{array}$ & Derivative & \# Params $^{1}$ & $\begin{array}{l}\text { Physiological } \\
\text { Interpretation }\end{array}$ & $\begin{array}{l}\text { Axenic } \\
\text { RMSE }^{2} \\
(n=13)\end{array}$ & $\begin{array}{l}\text { Co-culture } \\
\text { RMSE } \\
(n=343)\end{array}$ & Reference \\
\hline $\begin{array}{l}\text { Exponential } \\
X=X_{0} e^{-a t}\end{array}$ & $\frac{d X}{d t}=-a X$ & 1 & $\begin{array}{l}\text { Constant ratio of the } \\
\text { population dies in } \\
\text { each time point }\end{array}$ & $0.26 \pm 0.11$ & $0.29 \pm 0.21$ & $\begin{array}{l}\text { (Pruitt \& } \\
\text { Kamau, } \\
1993)\end{array}$ \\
\hline $\begin{array}{l}\text { Bi-Exponential } \\
\begin{array}{l}X \\
=X_{0}\left(f e^{-a_{1} t}\right. \\
\left.+(1-f) e^{-a_{2} t}\right)\end{array}\end{array}$ & $\begin{array}{l}\frac{d X}{d t}=-f a_{1} X_{1} \\
-(1-f) a_{2} X_{2}\end{array}$ & 3 & $\begin{array}{l}\text { Two subpopulations } \\
\text { with different } \\
\text { persistence under } \\
\text { stress and death rates }\end{array}$ & $0.26 \pm 0.11$ & $0.16 \pm 0.12$ & $\begin{array}{l}\text { (Crane \& } \\
\text { Moore, } \\
1986)\end{array}$ \\
\hline $\begin{array}{l}\text { Harmonic } \\
X=X_{0} \frac{1}{1+a t}\end{array}$ & $\frac{d X}{d t}=-a X^{2}$ & 1 & $\begin{array}{l}\text { Quadratic mortality } \\
\text { rate-dependence on } \\
\text { cell-cell encounters }\end{array}$ & $0.50 \pm 0.19$ & $0.19 \pm 0.13$ & $\begin{array}{l}\text { (Pruitt \& } \\
\text { Kamau, } \\
1993)\end{array}$ \\
\hline $\begin{array}{l}\text { Weibull } \\
X=X_{0} e^{-\frac{t^{n}}{a}}\end{array}$ & $\begin{array}{l}\frac{d X}{d t}= \\
-c t^{n-1} X^{*}\end{array}$ & 2 & $\begin{array}{l}\text { Probabilistic model } \\
\text { with a heterogeneous } \\
\text { distribution of stress } \\
\text { tolerance }\end{array}$ & $0.14 \pm 0.08$ & $0.18 \pm 0.11$ & $\begin{array}{l}\text { (Van } \\
\text { Boekel, } \\
\text { 2002) }\end{array}$ \\
\hline
\end{tabular}

${ }^{1}$ \# Params - number of free parameters

${ }^{2}$ RMSE - Root Mean Square Error 
a
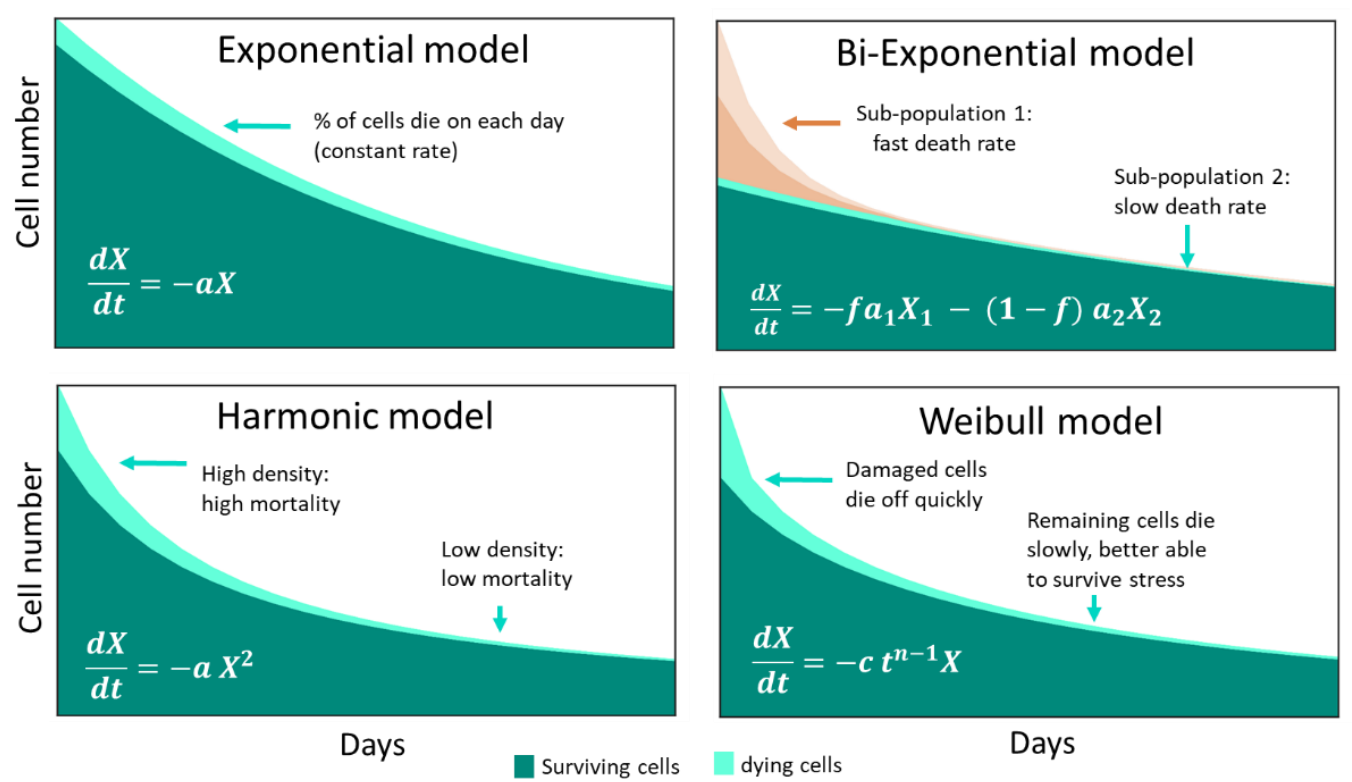

b
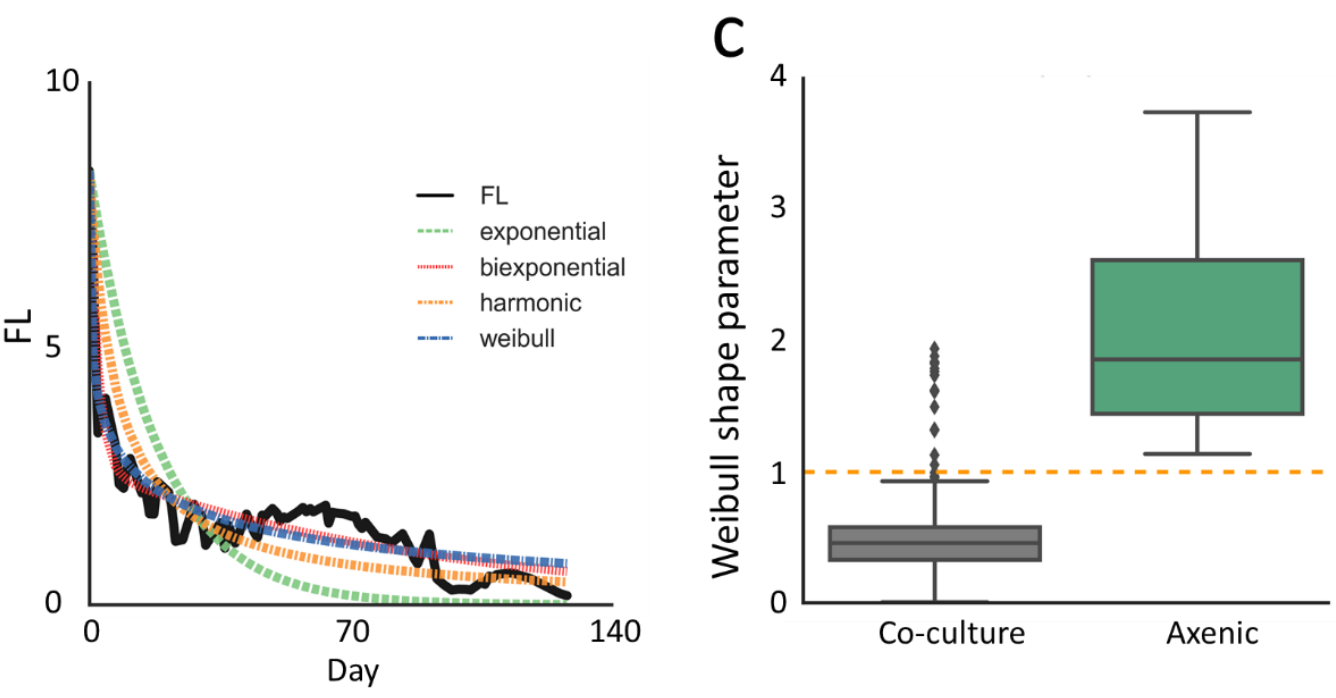

Fig 4: Modeling the mortality stage of axenic cultures and co-cultures. a. Graphical representation of four decline models. The lighter blue or peach colors represent the dying fraction of the population at each time-point. b. Comparison of the four decline models with co-culture of Prochlorococcus NATL2A with Alteromonas HOT1A3. While the Weibull model provides the best fit (see Table 1), none of the decline models fully describes the complexities of culture decline. c. Weibull Shape parameter $(\mathrm{n})$ in co-cultures vs axenic cultures (student ttest, $p<0.001)$. In all axenic samples $n>1$, and hence the decline rate increases over time. In most co-cultures $n<1$, suggesting that, as the culture declines, the remaining cells are better adapted to stress and thus their death rate decreases. 
In the Weibull model, the 'shape parameter' ( $n$ ) represents the change over time in the susceptibility of the bacterial community to stress. A shape parameter above one represents an increasing probability that cells will die as time increases (e.g. due to the accumulation of damage), whereas a shape parameter below one suggests that, over time, the cells become more resistant to damage. Axenic cultures have high shape value of $2.1 \pm 0.9$, suggesting an accumulation of cell damage leading to increasing death rate, whereas that of co-cultures is $0.5 \pm$ 0.3 (student t-test, $\mathrm{p}<0.001$ ) (Fig $4 \mathrm{c}$ ). This suggests that, in contrast to mono-cultures, in each cycle of co-culture the Prochlorococcus cells are acclimating over time to the nutrient stress conditions.

While the Weibull model is useful in quantifying mortality rates and raising the hypothesis that Prochlorococcus cells are acclimating to starvation over time, none of the tested models was able to fully capture the intricate dynamics of culture decline (Fig 4b). In most co-cultures involving Prochlorococcus strains NATL2A, MED4 and MIT0604, culture decline was not monotonic, and was interrupted by a second growth phase about 40-50 days after the cultures started declining. We propose that this "second breath" represents either a consistent shift in the physiology of one of the interacting partners (e.g. by activating pathways for the salvage of previously-exuded DOM) or a change in the availability of labile DOM, e.g. following a period of mortality and lysis of Prochlorococcus and/or Alteromonas. Because the second growth phase was mostly absent in MIT9312 and MIT9313, we speculate that this phenomenon, too, is driven primarily by the specific strain of Prochlorococcus cells in co-culture. Notably, the Weibull model, while best representing the experimental results, is less appropriate for ecological/biogeochemical models, because the time from peak is an inherent part of the differential equation. In such cases, the harmonic model formulation may be more appropriate, as it represents mortality of co-cultures better than exponential decline with the same number of parameters, and quadratic expressions for mortality are already used in such models (Dutkiewicz et al., 2001; S. K. Moore et al., 2006; Murray A.G. and Parslow J.S., 1999).

Accumulated mutations in Prochlorococcus suggest a role for nitrogen use and the 273 stringent response

During the experiments described above, we co-cultured strains of Prochlorococcus, which had each been previously maintained in axenic mono-cultures for hundreds or thousands of generations. We also exposed these parental strains, which are routinely maintained under conditions of exponential growth, to repeated cycles of growth, mortality and long-term survival under $\mathrm{N}$ starvation. To identify whether these shifts in life-style could result in genetic changes in the co-cultured populations, we re-sequenced the genomes of duplicate cultures of Prochlorococcus MIT9313 co-cultured with Alteromonas HOT1A3 after a total of 435 days in coculture (including 3 cycles of growth, mortality and survival, Fig 5a, Fig S1). We also re-sequenced the parental strain used in these experiments, which itself had been maintained as an axenic culture for $\sim 16$ years since originally being sequenced (Rocap et al., 2003). Since the read coverage for Alteromonas was low, we focus here on Prochlorococcus. 
Over the course of 435 days in co-culture ( 220 generations), the two replicate MIT9313 cocultures accumulated 32 and 39 observed mutations in protein-coding genes, compared to 57 mutations accumulated in the parental strain over $\sim 16$ years of growth at similar maximum population sizes ( 2,900 generations, $15-20 \mathrm{ml}$ cultures, Fig 5, Fig S8 and File S1). This suggests that, during the repeated cycles of growth, decline and starvation, the mutation rate of MIT9313 in co-culture increased roughly 7-9-fold compared to the parental axenic strain growing primarily exponentially (Supplementary text S2). Strikingly, many of the mutations were observed to occur in genes involved in nitrogen utilization and stress responses. Three genes involved in nitrogen metabolism each had two or more mutations associated with them - the nitrite reductase gene nirA and two genes in the operon involved in the production and transport of glycine betaine (Fig $5 b, c)$.

The parental MIT9313 strain had a frameshift mutation in the $\mathrm{N}^{\prime}$-terminal reductase domain of nirA, observed in $100 \%$ of the sequencing reads, which likely led to a truncated, inactive protein. This frameshift is not found in the evolved strain, after $\sim 220$ generations in co-culture. Since nitrite was not added to the (co)-cultures, and the Alteromonas genome does not contain the genes for nitrification (the ammonia monoxygenase gene), this raises the question of what are the sources of nitrite that is presumably being utilized by the evolved strain. We provide a speculative answer in Fig $5 \mathrm{~d}$. It has previously been shown, in the freshwater cyanobacterium Phormidium, that nitrite can be produced by the enzymatic dismutation of hydroxylamine $\left(\mathrm{NH}_{2} \mathrm{OH}\right)$ in the presence of hydrogen peroxide, $\mathrm{H}_{2} \mathrm{O}_{2}$ (reaction 3 in Fig 5 d, the other product is $\mathrm{NH}_{3}$ (Bagchi \& Kleiner, 1990, 1991)). $\mathrm{NH}_{2} \mathrm{OH}$, in turn, can be produced by the peroxidation of glutamine to glutamate (reaction 2 in Fig 5d, (Bagchi \& Kleiner, 1991)). The $\mathrm{H}_{2} \mathrm{O}_{2}$ required for these reactions is produced by multiple metabolic reactions in cyanobacteria (Latifi et al., 2009), and it has previously been shown that oxidative stress is enhanced during nitrogen starvation in Prochlorococcus (Mcdonagh et al., 2012). Thus, an active nitrite reductase may enable $\mathrm{MIT9313}$ to recycle $\mathrm{NH}_{2} \mathrm{OH}$, produced when the cells are under nitrogen starvation conditions (Fig $5 \mathrm{~d}$ ). Intriguingly, $\mathrm{H}_{2} \mathrm{O}_{2}$ is also produced during amino acid oxidation, the process in which cells degrade amino acids to obtain $\mathrm{N}$ and carbon backbones (e.g. by several types of L-amino acid oxidases, reaction 1 in Fig $5 d$, (Schriek et al., 2007)). It is currently unclear to what extent these amino acid degradation pathways are present and active in Prochlorococcus, as the streamlined genomes of these organisms lack several known enzymes (Gau et al., 2007; Schriek et al., 2007), although we note that a putative L-aspartate oxidase had a non-synonymous mutation in the evolved strains. If, however, nitrogen starvation induces amino acid oxidation and the production of $\mathrm{H}_{2} \mathrm{O}_{2}$ in Prochlorococcus, this would provide a mechanistic explanation for the inability of these organisms to survive long-term $\mathrm{N}$ starvation alone (J. Jeffrey Morris et al., 2008, 2012) Further studies are required to test this hypothesis.

Three genes in the operon for the production and import of the compatible solute glycine betaine accumulated mutations - the glycine-sarcosine methyltransferase gsmt, and two subunits of the glycine-betaine $A B C$ transporter (Fig $5 c$ ). None of the mutations occurred in residues known to be important to the activity of these proteins. Under $\mathrm{N}$ starvation, it is possibly advantageous for the cells to reduce the production of glycine betaine, which contains $\mathrm{N}$ atoms, in favor of other compatible solutes such as sucrose (Klähn et al., 2010). However, during the long experiments described here, it is also likely that the osmotic strength of the growth media increased (due to 
328 both cell lysis and the evaporation of water), and this could lead to an increased requirement for 329 glycine betaine (Klähn et al., 2010). Further work is needed in order to differentiate between these 330 two hypotheses. Importantly, glycine betaine provides both carbon (energy) and $\mathrm{N}$ to co-occurring 331 bacteria, including SAR11 (Becker et al., 2019). Additional genes involved in N metabolism that 332 accumulated non-synonymous mutations (one for each gene) include enzymes involved in amino 333 acids production or degradation (the L-aspartate oxidase mentioned above, biosynthetic arginine 334 decarboxylase and cysteine synthase) and a putative aminotransferase (Fig 5b, File S1). Genetic 335 changes occurred in additional genes not directly related to nitrogen metabolism, but known to 336 be involved in the nitrogen stress response in cyanobacteria. These include the glycogen synthase 337 gene glgA (Tolonen et al., 2006) as well as genes involved in the synthesis of chlorophyll and other 338 proteins from the photosynthetic apparatus.

339 Finally, the bacterial "alarmone" (p)ppGpp is a master regulator of bacterial stress responses, 340 including the "stringent response" to carbon or amino acid starvation (recently reviewed by 341 (Steinchen \& Bange, 2016)). Two mutations were observed in a gene homologous to the relA/spoT 342 bifunctional (p)ppGpp synthase/hydrolase. The product of this gene both activates the stringent 343 response by synthesizing (p)ppGpp from GTP and represses it, by hydrolyzing the alarmone back 344 to GTP (Hogg et al., 2004; Steinchen \& Bange, 2016). Both of the mutations were in the hydrolase 345 domain, and one of them (P95T) occurs in a residue which is predicted to take part in $\mathrm{Mn}$ 346 coordination in the active site of the enzyme, potentially leading to a hydrolase-incompetent 347 enzyme (Hogg et al., 2004; Steinchen \& Bange, 2016). We speculate that this mutant may be 348 deficient in its ability to "turn off" the stringent response, potentially leading to enhanced survival 349 under stress. 


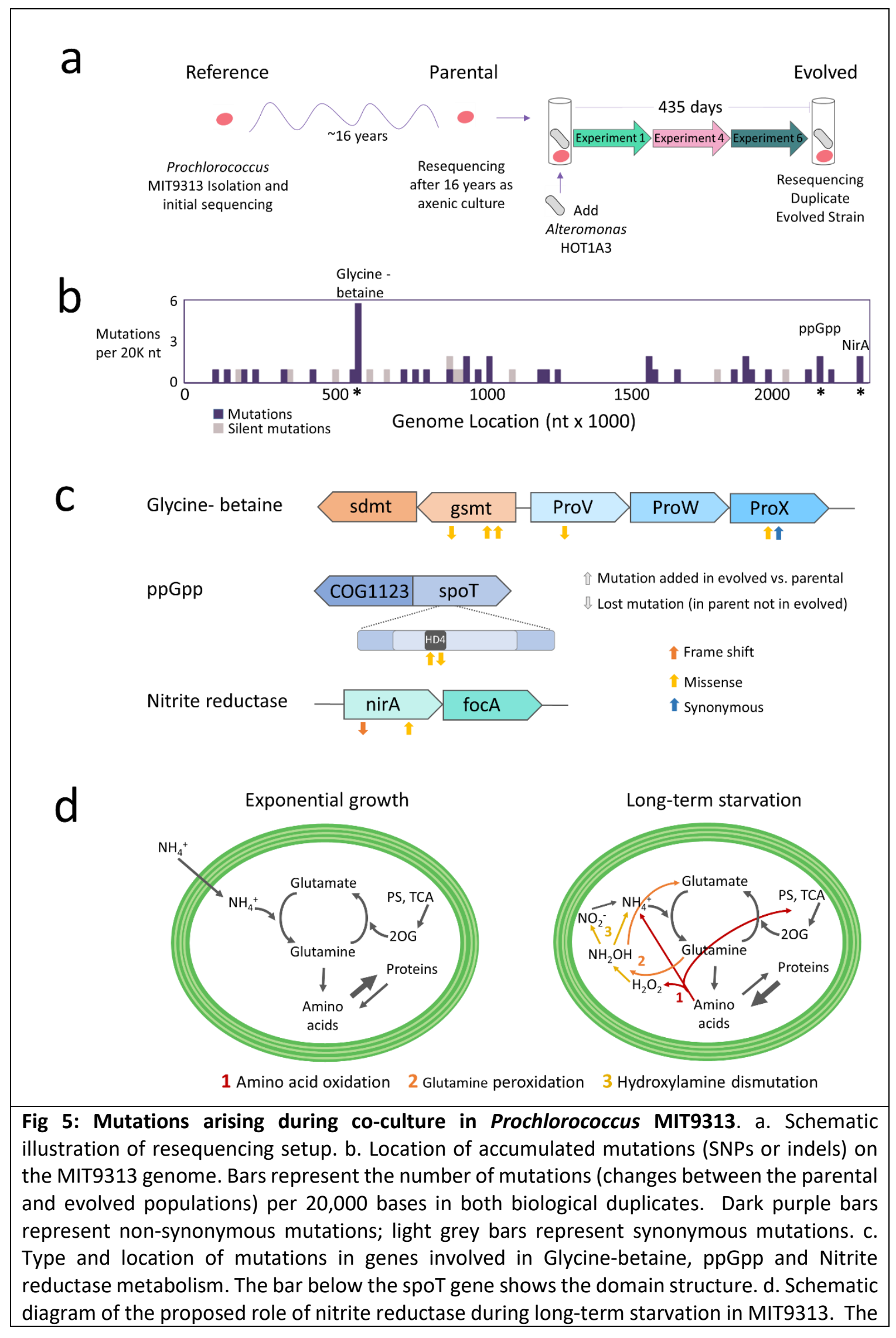


suggested pathway leading to the production of nitrite $\left(\mathrm{NO}_{2}^{-}\right)$through hydroxylamine $\left(\mathrm{NH}_{2} \mathrm{OH}\right)$ is shown in long term starvation compared to exponential growth. The balanced equations for this pathway are: Reaction 1 - amino acid oxidation by L-amino acid oxidases (e.g. Alanine + $\mathrm{H}_{2} \mathrm{O}+\mathrm{O}_{2} \rightarrow$ Pyruvate $+\mathrm{NH}_{4}{ }^{+}+\mathrm{H}_{2} \mathrm{O}_{2}$ ); Reaction 2 - Peroxidation of glutamine to glutamate $\left(\mathrm{C}_{5} \mathrm{H}_{10} \mathrm{~N}_{2} \mathrm{O}_{3}+\mathrm{H}_{2} \mathrm{O}_{2}->\mathrm{C}_{5} \mathrm{H}_{9} \mathrm{NO}_{4}+\mathrm{NH}_{2} \mathrm{OH}\right)$; Reaction 3 - Dismutation of hydroxylamine in the presence of $\mathrm{H}_{2} \mathrm{O}_{2}\left(2 \mathrm{NH}_{2} \mathrm{OH}+\mathrm{H}_{2} \mathrm{O}_{2}->\mathrm{NO}_{2}^{-}+\mathrm{NH}_{4}{ }^{+}+2 \mathrm{H}_{2} \mathrm{O}\right)$. PS - photosynthesis, TCA tricarboxylic acid cycle, 2OG - 2-oxoglutarate

\section{Summary and future directions}

353 As our appreciation of the richness and dynamicity of microbial communities increases, so does 354 the understanding that interactions between microorganisms are critical to the structure and 355 function of these communities. Elucidating the roles of microbial interactions requires both well356 characterized model organisms and a way to extend the insights from such models across the 357 diversity of organisms and environmental conditions. Our results from the highly-simplified 358 system of multiple Prochlorococcus and Alteromonas strains provide an important step towards this goal. Using the rich information on interaction phenotypes present in the growth and decline curves, we identify conserved and strain-specific facets of these interactions. Despite the genetic diversity across the Alteromonas strains studied, it was the identity of the Prochlorococcus strain that determined the interaction phenotype. This manifests in the growth and decline rates, in the shape of the curve (primarily the decline phase), and in the number of cells living in long-term, nitrogen-starved co-culture. Testing multiple mathematical models of culture decline suggests that cells in axenic cultures are accumulating damage and dying more rapidly over time, while cells in co-culture are acclimating, likely changing their physiology and also evolving to better deal with the emergent stress. Comparing the modelled and observed curves allows for the identification of consistent and reproducible shifts in physiology, for example the "second breath" of growth followed by rapid decline in NATL2A co-cultures (Fig $4 b$ ), that can then be studied indepth.

Under our laboratory conditions, it is likely that nitrogen starvation is the main selection force driving the phenotypic outcome of long-term co-cultures, although other stressors such as the increase in osmolarity/salinity or the accumulation of waste products cannot be ruled out. We speculate that the genetic changes observed in the MIT9313 population are primarily indicative of processes occurring in the Prochlorococcus cells due to nitrogen starvation and/or osmotic stress, rather than representing a direct response to the interactions with Alteromonas. It is possible that a major effect of co-culture with Alteromonas is to slow down the deterioration in Prochlorococcus homeostasis, providing a "buffer" that enables Prochlorococcus to activate its own starvation survival responses, and subsequently to genetically evolve. Alteromonas may similarly allow Prochlorococcus to adapt to light starvation (Coe et al., 2016), yet the genetic mechanisms underlying this survival remain unclear (Coe et al., 2020). However, the buffering effect of Alteromonas cannot be taken for granted, as it also depends on culture conditions, for example $\mathrm{CO}_{2}$ concentrations (Hennon et al., 2018). 
differences in nitrogen metabolism. For example, Prochlorococcus MIT9313 produces glycine betaine as a compatible solute (unlike MIT9312 and NATL2A (Klähn et al., 2010)), and it is possible that producing large amounts of this $\mathrm{N}$-containing molecule constrains the metabolic responses of this strain to $\mathrm{N}$ starvation differently from other strains, resulting in this strain having a distinct phenotype. The reasons for the differences between the other Prochlorococcus strains are less clear, but may be related to differences in the regulatory networks (e.g. those affected by the ppGpp alarmone) or the capacity to utilize organic substances released by Alteromonas (Yelton et al., 2016). Some of the mutations were in hypothetical genes and in some cases in multiple hypothetical genes in the same putative operon (e.g. PMT1541 and PMT1542). Future work is needed to determine whether these represent "internal" Prochlorococcus processes, or whether they are part of the tools used by Prochlorococcus to interact with co-occurring bacteria.

Why is it the identity of the primary producer (Prochlorococcus) rather than the heterotrophic "recycler" (Alteromonas) that determines the outcome of the co-culture? A-priori, it was reasonable to assume that the co-culture phenotype would be affected by the differences between the Alteromonas strains in their ability to degrade and utilize polysaccharides and a variety of other organic molecule (Koch et al., 2019, 2020). We speculate that the growth of Alteromonas in the co-cultures is fueled primarily by the availability of major biomass components released by Prochlorococcus as they die, such as proteins, amino acids and nucleotides. Such common macromolecules do not require highly specialized metabolic processes to degrade and utilize, and hence could be utilized by all of the Alteromonas strains. It is possible that the differences between Alteromonas strains may manifest when more complex macromolecules are available, e.g. from plant material, or when all of the "easy to digest" (labile) organic matter has been utilized and only complex macromolecules remain (Teeling et al., 2012). These conditions may not have been met in our experiments. Regardless of the underlying mechanism, identifying to what extent the interaction phenotype is dependent on the identity of each of the interacting organisms requires an experimental setup spanning the diversity of both.

Our results identify patterns in the interactions between clades of abundant marine phototrophs and heterotrophs, including consistent shifts in physiology occurring after extended time in coculture. The mechanistic basis of these shifts in physiology can now be studied in-depth. Given that these shifts occur under conditions where nutrients are scarce and their availability likely depends on recycling between phototrophs and heterotrophs, it is tempting to speculate that such mechanisms may be physiologically relevant in the oligotrophic ocean, much of which is $\mathrm{N}$ stressed (Ustick et al., 2021). Nevertheless, the co-cultures did not reach a steady state, and did not represent a closed system. Thus, processes not represented in these simplified laboratory cocultures, are necessary to explain the long-term stability over decades of Prochlorococcus in the oceans (Malmstrom et al., 2010). Such processes could include multi-organism interactions, as natural communities are much more complex than the laboratory co-cultures, as well as oceanographic processes such as nutrient injection through deep mixing. More generally, cell mortality is intimately linked with the amount and type of recycled organic matter, yet the rate of mortality in natural communities is highly unconstrained (Beckett et al., 2021). Hence, better representation of mortality in mathematical models (e.g. the use of appropriate mortality formulations) is likely important for understanding biogeochemical cycles (Beckett et al., 2021). Finally, this study is a reminder that bacterial growth curves represent an information-rich 
representation of the life and death of cells, which can be mined to identify potential physiological changes of ecological relevance.

\section{Materials and Methods}

\section{Strains and experiment set up}

434 Axenic Prochlorococcus strains MED4, MIT9312, MIT0604, NatI2A and MIT9313 were maintained 435 in Low N Pro99 media, based on natural sea water, with the addition of $100 \mu \mathrm{M}$ nitrogen, $50 \mu \mathrm{M}$ phosphorus and trace metal elements. Under these conditions, Prochlorococcus enter stationary stage due to the depletion of $\mathrm{NH}_{4}$ from the media and nitrogen starvation (Grossowicz et al., 2017). Alteromonas strains HOT1A3, Black sea 11, ATCC27126, AltDE1 and AltDE were maintained in ProMM media. both under constant cold while light $\left(27 \mu \mathrm{Em}^{-2} \mathrm{~s}^{-1}\right)$ at $22^{\circ} \mathrm{C}$ in (L. R. Moore et al., 2007; Sher et al., 2011)). Prior to the experiment, the axenicity of the Prochlorococcus cultures was tested by inoculating $1 \mathrm{ml}$ culture into $15 \mathrm{ml}$ ProMM (L. R. Moore et al., 2007)). At the start of each co-culture experiment, Alteromonas cells from stationary-stage cultures (24-72 hour old) were centrifuged (15 minutes, room temperature, 15,000g), the growth media decanted, and the cells re-suspended in Pro99. The Prochlorococcus cultures (growing exponentially) and the resuspended Alteromonas cells were then counted using BD FACSCanto ${ }^{\mathrm{TM}}$ II Flow Cytometry Analyzer Systems (BD Biosciences). For each co-culture, $1 \times 10^{6}$ Prochlorococcus cells mixed with $1 \times 10^{7}$ Alteromonas cells. For mono-cultures, $1 \times 10^{6}$ and $1 \times 10^{7}$ were added for Prochlorococcus and Alteromonas, respectively. The experiment was performed using triplicate $20 \mathrm{ml}$ cultures in

\section{Fluorescence and Flow cytometry}

452 Bulk chlorophyll fluorescence (FL) (ex440; em680) was measured almost daily using a 453 Fluorescence Spectrophotometer (Cary Eclipse, Varian). Samples for flow cytometry were taken 454 for cell numbers after 60, 100 and 140 days of experiment 1 (Fig S1). Samples were fixed with glutaraldehyde $(0.125 \%$ final concentration), incubated in the dark for 10 min and stored in -80 ${ }^{\circ} \mathrm{C}$ until analysis. Then, samples were thawed at room temperature and run on a BD FACSCanto ${ }^{\mathrm{TM}}$ II Flow Cytometry Analyzer Systems (BD Biosciences). To each sample, $2 \mu \mathrm{m}$ diameter fluorescent beads (Polysciences, Warminster, PA, USA) were added as an internal standard. At first, the natural fluorescence of the cells (chlorophyll pigments) was examined to identify Prochlorococcus, identified based on the PerCP-A and FSC-H. Samples were then stained with SYBR Green I (Molecular Probes/ ThermoFisher) to a final concentration according to the manufacturer's instructions and the Alteromonas was counted. Data were acquired and processed with FlowJo software. Flow rates were determined several times during each running session, and the average 
PCA ordination was run on the growth curves. The Cumulative sum of Fluorescence measurements were standardized via standard scalar by subtracting the mean and scaling to unit variance of each feature. Ordination was computed via principal component analysis (PCA). Data preprocessing was done by pandas (0.25.0). Scaling and PCA was done using sklearn (0.21.2).

\section{Growth rate}

472 Growth was computed - by solving the equation:

$$
N_{t}=N_{0} e^{\mu(t-L)}
$$

474 Where $N_{t}$ represents the number of cells at time $t, N_{0}$ is the initial number of cells, $\mu$ is the growth 475 rate, and $L$ is the growth lag. The LAN transformed equation was used to compute growth rate:

$$
\ln \left(N_{t}\right)=\ln \left(N_{0}\right)+\mu(t-L)
$$

477 Linear regression was run on the growth phase, predicting $\ln \left(N_{t}\right)$ based on time $t$ with $\mathrm{R}^{2}>0.9$. 478 The growth rate $\mu$ is the regression coefficient.

\section{Fit to Decline models}

480 The following functions were used to fit against the measured fluorescence:

Where $F L_{t}$ is the Fluorescence measured at time $t, F L_{\max }$ is the maximum fluorescence measured, $t_{\max }$ is the time when the fluorescence was highest, and $a, a 1, a 2, n, f$ are the model parameters estimated by the fitting function.

488 The decline function was fit against each growth curve via curve_fit() function from scipy package 489 (1.3.0), using the parameters: method='dogbox', loss='soft_l1', f_scale=0.1. Each model was fit 490 using random initial parameter values and the initial values of 0.5 per parameter, and the fit with 491 the lowest RSME selected. Goodness of fit was measures using root mean square error (RMSE).

492 In the Weibull model the time needed to reduce the population by $d$ factors of $10\left(t_{d 2}\right)$ was 493 estimated as in (Van Boekel, 2002), using the formula:

$$
t_{d}=a\left(-\ln \left(10^{-d}\right)^{\frac{1}{n}}\right)
$$




\section{Random Forest Classification}

496 Random Forest Classification was run on the growth curves. To detect difference in the curve pattern and not timing specific differences, the curves were aligned such that max growth point 498 are at time zero, and time points from 10 days prior to max growth to 80 days after were selected. 499 Since the specific measurement time points were different in different experiments and samples, rolling average was used to get mean fluorescence per day, and interpolation used to fill in missing measurements. The Fluorescence measurements were standardized via standard scalar by subtracting the mean and scaling to unit variance of each feature. Random Forest model was run in $10 x$ cross validation to classify the curves by Prochlorococcus and by Alteromonas strains. To find the most significant days in Prochlorococcus classification, the model was built 30 times and the mean importance of all features (i.e., measurement days) calculated. Data preprocessing was done by pandas (0.25.0). Scaling and model fitting using sklearn (0.21.2).

Statistics were computed using the statsmodels package in python. Multi test correction was done by t_test_pairwise() using Bonferroni correction. Permanova analysis by adonis 2 from $\mathrm{R}$ vegan package (R 3.61, vegan 2.5-7).

DNA extraction, genome resequencing and SNP analysis

Samples for genomic DNA sequencing was collected from parental strains, before experiment 1 and after 435 days from co-cultures (Fig S1, Fig 5a). Samples collected on a $0.22 \mu \mathrm{m}$ filter (Supor, Pall Corporation), filled with $1 \mathrm{ml}$ of storage buffer (40 mM EDTA, $50 \mathrm{mM}$ Tris $\mathrm{pH}=8.3,0.75 \mathrm{M}$ Soucrose) and stored at $-80^{\circ} \mathrm{C}$. Before extraction samples were thawed on ice and storage buffer removed carefully. DNA extracted using DNeasy PowerWater Kit (Qiagen) according to the kit's protocol. DNA samples (minimum concentration of $1 \mathrm{ng} / \mathrm{uL}$ ) were submitted to the MIT BioMicroCenter in 96 well plate format. Samples were prepared for sequencing using Nextera flex preparation for intact DNA (high throughput) and a size selection of 300-600bp. DNA was sequenced using MiSeq flowcell (v3, 600nt). The samples have been processed using the BMC/BCC 1.7 pipeline updated on 01/11/2019. The NexteraPE adapter and the first 20 bases were trimmed by trimmomatic $0.39-1$. And quality checked using fastqc and multiqc. All samples were mapped to the reference genome and variant called using snippy (based on bwa mem mapping, freebayes variant call, snpEff annotation). Alteromonas reads were removed from Co-culture samples by first mapping to Alteromonas HOT1A3 (NCBI accession: NZ_CP012202.1, NZ_CP012203.1), then running snippy a second time on reads that were not mapped to Alteromonas, mapping against Prochlorococcus MIT9313 (NCBI accession: NC_005071.1). The number of reads per sample was 550K-610K, 98-99\% of the reads were mapped successfully to MIT9313 genome yielding mean coverage of $29-42 X, 99-100 \%$ of the genes had $>10 X$ coverage. Mapping quality was assessed using qualimap. SNPs were called only if the read depth was at lease 10 and the Genotype Quality, the Phred-scaled marginal (or unconditional) probability of the called genotype was at least 20. All raw reads can be downloaded from the NCBI Sequence 


\section{Acknowledgements}

537 Daniel Segrè and Melisa Osborne for help with sequencing, Sher lab members and especially 538 Natalie Andrawes for help in fluorescence measurements. Hans-Peter Grossart, Zhen Wu and Tal 539 Luzzatto Knaan for critical reading of the manuscript. This work was supported by the Human 540 Frontiers Science Program (grant RGP0020/2016, to DS) and the U.S.-Israel Binational Science 541 Foundation (BSF) - U.S. National Science Foundation (NSF) program in Oceanography (grant 542 1635070/2016532, to DS). The funders had no role in study design, data collection and analysis, 543 decision to publish, or preparation of the manuscript.

\section{References}

Aharonovich, D., \& Sher, D. (2016). Transcriptional response of Prochlorococcus to co-culture with a marine Alteromonas: Differences between strains and the involvement of putative infochemicals. ISME Journal, 10(12), 2892-2906. https://doi.org/10.1038/ismej.2016.70

Amin, S. A., Hmelo, L. R., Van Tol, H. M., Durham, B. P., Carlson, L. T., Heal, K. R., Morales, R. L., Berthiaume, C. T., Parker, M. S., Djunaedi, B., Ingalls, A. E., Parsek, M. R., Moran, M. A., \& Armbrust, E. V. (2015). Interaction and signalling between a cosmopolitan phytoplankton and associated bacteria. Nature, 522(7554), 98-101. https://doi.org/10.1038/nature14488

Antoniewicz, M. R. (2020). A guide to deciphering microbial interactions and metabolic fluxes in microbiome communities. Current Opinion in Biotechnology, 64, 230-237. https://doi.org/10.1016/j.copbio.2020.07.001

Bagchi, S. N., \& Kleiner, D. (1990). Dismutation of hydroxylamine to ammonia and nitrite by a novel, membrane-bound enzyme from the cyanobacterium Phormidium uncinatum. Biochimica et Biophysica Acta (BBA)/Protein Structure and Molecular, 1041(1), 9-13. https://doi.org/10.1016/0167-4838(90)90115-V

Bagchi, S. N., \& Kleiner, D. (1991). Interrelationship between hydrogen peroxide, ammonia, glutamine, hydroxylamine and nitrite metabolism in the cyanobacterium Phormidium uncinatum. Archives of Microbiology, 156(5), 367-369. https://doi.org/10.1007/BF00248712

Becker, J. W., Hogle, S. L., Rosendo, K., \& Chisholm, S. W. (2019). Co-culture and biogeography of Prochlorococcus and SAR11. ISME Journal, 13(6), 1506-1519. https://doi.org/10.1038/s41396-019-0365-4

Beckett, S. J., Demory, D., Coenen, A. R., Casey, J. R., Dugenne, M., Follett, C. L., Connell, P., Carlson, M. C. G., Hu, S. K., Wilson, S. T., Becker, K. W., Mende, D. R., Armbrust, E. V., White, A. E., Ribalet, F., \& Weitz, J. S. (2021). Diel population dynamics and mortality of Prochlorococcus in the North Pacific Subtropical Gyre. 1-20.

Biller, S. J., Berube, P. M., Lindell, D., \& Chisholm, S. W. (2015). Prochlorococcus: The structure and function of collective diversity. Nature Reviews Microbiology, 13(1), 13-27. https://doi.org/10.1038/nrmicro3378 
Biller, S. J., Coe, A., \& Chisholm, S. W. (2016). Torn apart and reunited: Impact of a heterotroph on the transcriptome of Prochlorococcus. ISME Journal, 10(12), 2831-2843. https://doi.org/10.1038/ismej.2016.82

Brouwer, A. F., Eisenberg, M. C., Remais, J. V., Collender, P. A., Meza, R., \& Eisenberg, J. N. S. (2017). Modeling Biphasic Environmental Decay of Pathogens and Implications for Risk Analysis. Environmental Science and Technology, 51(4), 2186-2196. https://doi.org/10.1021/acs.est.6b04030

Christie-Oleza, J. A., Sousoni, D., Lloyd, M., Armengaud, J., \& Scanlan, D. J. (2017). Nutrient recycling facilitates long-term stability of marine microbial phototroph-heterotroph interactions. Nature Microbiology, 2(June). https://doi.org/10.1038/nmicrobiol.2017.100

Cirri, E., \& Pohnert, G. (2019). Algae-bacteria interactions that balance the planktonic microbiome. New Phytologist, 223(1), 100-106. https://doi.org/10.1111/nph.15765

Coe, A., Biller, S. J., Thomas, E., Boulias, K., Bliem, C., Dooley, K., Rasmussen, A. N., Legault, K., Keefe, T. J. O., Eric, L., \& Chisholm, S. W. (2020). Coping with darkness: The adaptive response of marine picocyanobacteria to repeated light energy deprivation. 1-32.

Coe, A., Ghizzoni, J., LeGault, K., Biller, S., Roggensack, S. E., \& Chisholm, S. W. (2016). Survival of Prochlorococcus in extended darkness. Limnology and Oceanography, 61(4), 1375-1388. https://doi.org/10.1002/Ino.10302

\section{Cole, J. J. (1982). INTERACTIONS BETWEEN. 291-314.}

Cordero, O. X., Wildschutte, H., Kirkup, B., Proehl, S., Ngo, L., Hussain, F., Le Roux, F., Mincer, T., Polz, M. F., \& Roux, F. Le. (2012). Ecological Populations of BacteriaAct as Socially Cohesive Units ofAntibiotic Production and Resistance. Science (New York, N.Y.), 337(September), 1228-1231. https://doi.org/10.1126/science.1219385

Crane, S. R., \& Moore, J. A. (1986). Modeling enteric bacterial die-off: A review. Water, Air, \& Soil Pollution, 27(3-4), 411-439. https://doi.org/10.1007/BF00649422

Cubillos-Ruiz, A., Berta-Thompson, J. W., Becker, J. W., Van Der Donk, W. A., \& Chisholm, S. W. (2017). Evolutionary radiation of lanthipeptides in marine cyanobacteria. Proceedings of the National Academy of Sciences of the United States of America, 114(27), E5424-E5433. https://doi.org/10.1073/pnas.1700990114

Diner, R. E., Schwenck, S. M., McCrow, J. P., Zheng, H., \& Allen, A. E. (2016). Genetic manipulation of competition for nitrate between heterotrophic bacteria and diatoms. Frontiers in Microbiology, 7(JUN). https://doi.org/10.3389/fmicb.2016.00880

Dutkiewicz, S., Follows, M., Marshall, J., \& Gregg, W. W. (2001). Interannual variability of phytoplankton abundances in the North Atlantic. Deep Sea Research Part II: Topical Studies in Oceanography, 48(10), 2323-2344.

Field, C. B., Behrenfeld, M. J., Randerson, J. T., \& Falkowski, P. (1998). Primary production of the biosphere: Integrating terrestrial and oceanic components. Science, 281(5374), 237-240. https://doi.org/10.1126/science.281.5374.237

Finkel, S. E., \& Kolter, R. (1999). Evolution of microbial diversity during prolonged starvation. Proceedings of the National Academy of Sciences of the United States of America, 96(7), 
615

Foster, K. R., \& Bell, T. (2012). Competition, not cooperation, dominates interactions among culturable microbial species. Current Biology, 22(19), 1845-1850. https://doi.org/10.1016/j.cub.2012.08.005

Fritts, R. K., McCully, A. L., \& McKinlay, J. B. (2021). Extracellular Metabolism Sets the Table for Microbial Cross-Feeding. Microbiology and Molecular Biology Reviews, 85(1). https://doi.org/10.1128/mmbr.00135-20

Gau, A. E., Heindl, A., Nodop, A., Kahmann, U., \& Pistorius, E. K. (2007). L-amino acid oxidases with specificity for basic L-amino acids in cyanobacteria. Zeitschrift Fur Naturforschung Section C Journal of Biosciences, 62(3-4), 273-284. https://doi.org/10.1515/znc-2007-3419

Gralka, M., Szabo, R., Stocker, R., \& Cordero, O. X. (2020). Trophic Interactions and the Drivers of Microbial Community Assembly. Current Biology, 30(19), R1176-R1188. https://doi.org/10.1016/j.cub.2020.08.007

Grossart, H. P. (1999). Interactions between marine bacteria and axenic diatoms (Cylindrotheca fusiformis, Nitzschia laevis, and Thalassiosira weissflogii) incubated under various conditions in the lab. Aquatic Microbial Ecology, 19(1), 1-11. https://doi.org/10.3354/ame019001

Grossart, H. P., \& Simon, M. (2007). Interactions of planktonic algae and bacteria: Effects on algal growth and organic matter dynamics. Aquatic Microbial Ecology, 47(2), 163-176. https://doi.org/10.3354/ame047163

Grossowicz, M., Roth-Rosenberg, D., Aharonovich, D., Silverman, J., Follows, M. J., \& Sher, D. (2017). Prochlorococcus in the lab and in silico: The importance of representing exudation. Limnology and Oceanography, 62(2), 818-835. https://doi.org/10.1002/Ino.10463

Hackl, T., Laurenceau, R., Ankenbrand, M. J., Bliem, C., Cariani, Z., Thomas, E., Dooley, K. D., Arellano, A. A., Hogle, S. L., Berube, P., Leventhal, G. E., Luo, E., Eppley, J., Zayed, A. A., Beaulaurier, J., Stepanauskas, R., Sullivan, M. B., DeLong, E. F., Biller, S. J., \& Chisholm, S. W. (2021). Novel Integrative Elements and Genomic Plasticity in Ocean Ecosystems. SSRN Electronic Journal. https://doi.org/10.2139/ssrn.3817805

Harrington, V., Lau, L., Seddu, K., \& Suez, J. (2021). Ecology and Medicine Converge at the Microbiome-Host. 6(4), 4-8.

Hennon, G. M., Morris, J. J., Haley, S. T., Zinser, E. R., Durrant, A. R., Entwistle, E., Dokland, T., \& Dyhrman, S. T. (2018). The impact of elevated CO 2 on Prochlorococcus and microbial interactions with â € helper' bacterium Alteromonas. ISME Journal, 12(2), 520-531. https://doi.org/10.1038/ismej.2017.189

Hogg, T., Mechold, U., Malke, H., Cashel, M., \& Hilgenfeld, R. (2004). Conformational antagonism between opposing active sites in a bifunctional RelA/SpoT homolog modulates (p)ppGpp metabolism during the stringent response. Cell, 117(1), 57-68. https://doi.org/10.1016/S0092-8674(04)00260-0

Hou, S., López-Pérez, M., Pfreundt, U., Belkin, N., Stüber, K., Huettel, B., Reinhardt, R., BermanFrank, I., Rodriguez-Valera, F., \& Hess, W. R. (2018). Benefit from decline: The primary 
transcriptome of Alteromonas macleodii str. Te101 during Trichodesmium demise. ISME Journal, 12(4), 981-996. https://doi.org/10.1038/s41396-017-0034-4

Kettler, G. C., Martiny, A. C., Huang, K., Zucker, J., Coleman, M. L., Rodrigue, S., Chen, F., Lapidus, A., Ferriera, S., Johnson, J., Steglich, C., Church, G. M., Richardson, P., \& Chisholm, S. W. (2007). Patterns and implications of gene gain and loss in the evolution of Prochlorococcus. PLoS Genetics, 3(12), 2515-2528. https://doi.org/10.1371/journal.pgen.0030231

Klähn, S., Steglich, C., Hess, W. R., \& Hagemann, M. (2010). Glucosylglycerate: A secondary compatible solute common to marine cyanobacteria from nitrogen-poor environments. Environmental Microbiology, 12(1), 83-94. https://doi.org/10.1111/j.14622920.2009.02045.x

Koch, H., Dürwald, A., Schweder, T., Noriega-Ortega, B., Vidal-Melgosa, S., Hehemann, J. H., Dittmar, T., Freese, H. M., Becher, D., Simon, M., \& Wietz, M. (2019). Biphasic cellular adaptations and ecological implications of Alteromonas macleodii degrading a mixture of algal polysaccharides. ISME Journal, 13(1), 92-103. https://doi.org/10.1038/s41396-0180252-4

Koch, H., Germscheid, N., Freese, H. M., Noriega-Ortega, B., Lücking, D., Berger, M., Qiu, G., Marzinelli, E. M., Campbell, A. H., Steinberg, P. D., Overmann, J., Dittmar, T., Simon, M., \& Wietz, M. (2020). Genomic, metabolic and phenotypic variability shapes ecological differentiation and intraspecies interactions of Alteromonas macleodii. Scientific Reports, 10(1), 1-14. https://doi.org/10.1038/s41598-020-57526-5

Latifi, A., Ruiz, M., \& Zhang, C. C. (2009). Oxidative stress in cyanobacteria. FEMS Microbiology Reviews, 33(2), 258-278. https://doi.org/10.1111/j.1574-6976.2008.00134.x

Li, B., Sher, D., Kelly, L., Shi, Y., Huang, K., Knerr, P. J., Joewono, I., Rusch, D., Chisholm, S. W., \& Van Der Donk, W. A. (2010). Catalytic promiscuity in the biosynthesis of cyclic peptide secondary metabolites in planktonic marine cyanobacteria. Proceedings of the National Academy of Sciences of the United States of America, 107(23), 10430-10435. https://doi.org/10.1073/pnas.0913677107

Long, R. A., \& Azam, F. (2001). Microscale patchiness of bacterioplankton assemblage richness in seawater. Aquatic Microbial Ecology, 26(2), 103-113. https://doi.org/10.3354/ame026103

López-Pérez, M., \& Rodriguez-Valera, F. (2016). Pangenome evolution in themarine bacterium alteromonas. Genome Biology and Evolution, 8(5), 1556-1570. https://doi.org/10.1093/gbe/evw098

Malmstrom, R. R., Coe, A., Kettler, G. C., Martiny, A. C., Frias-Lopez, J., Zinser, E. R., \& Chisholm, S. W. (2010). Temporal dynamics of Prochlorococcus ecotypes in the Atlantic and pacific oceans. ISME Journal, 4(10), 1252-1264. https://doi.org/10.1038/ismej.2010.60

Mcdonagh, B., Domínguez-Martín, M. A., Gómez-Baena, G., López-Lozano, A., Diez, J., Bárcena, J. A., \& García Fernández, J. M. (2012). Nitrogen starvation induces extensive changes in the redox proteome of Prochlorococcus sp. strain SS120. Environmental Microbiology Reports, 4(2), 257-267. https://doi.org/10.1111/j.1758-2229.2012.00329.x

Monod, J. (1949). a Certain Number. Annual Reviews in M, 3(XI), 371-394.

Moore, L. R., Coe, A., Zinser, E. R., Saito, M. A., Sullivan, M. B., Lindell, D., Frois-Moniz, K., 
Waterbury, J., \& Chisholm, S. W. (2007). Culturing the marine cyanobacterium Prochlorococcus. Limnology and Oceanography: Methods, 5(OCT), 353-362. https://doi.org/10.4319/lom.2007.5.353

Moore, S. K., Baird, M. E., \& Suthers, I. M. (2006). Relative effects of physical and biological processes on nutrient and phytoplankton dynamics in a shallow estuary after a storm event. Estuaries and Coasts, 29(1), 81-95. https://doi.org/10.1007/BF02784701

Morris, J. J., Johnson, Z. I., Szul, M. J., Keller, M., \& Zinser, E. R. (2011). Dependence of the cyanobacterium Prochlorococcus on hydrogen peroxide scavenging microbes for growth at the ocean's surface. PLoS ONE, 6(2). https://doi.org/10.1371/journal.pone.0016805

Morris, J. Jeffrey, Kirkegaard, R., Szul, M. J., Johnson, Z. I., \& Zinser, E. R. (2008). Facilitation of robust growth of Prochlorococcus colonies and dilute liquid cultures by "helper" heterotrophic bacteria. Applied and Environmental Microbiology, 74(14), 4530-4534. https://doi.org/10.1128/AEM.02479-07

Morris, J. Jeffrey, Lenski, R. E., \& Zinser, E. R. (2012). The black queen hypothesis: Evolution of dependencies through adaptive gene loss. MBio, 3(2), 1-7. https://doi.org/10.1128/mBio.00036-12

Murray A.G. and Parslow J.S. (1999). The analysis of alternative formulations in a simple model of a coastal ecosystem. Ecological Modelling, 119(2-3), 149-166.

Pacheco, A. R., Osborne, M. L., \& Segrè, D. (2021). Non-additive microbial community responses to environmental complexity. Nature Communications, 12(1), 1-11. https://doi.org/10.1038/s41467-021-22426-3

Patra, P., \& Klumpp, S. (2013). Population Dynamics of Bacterial Persistence. PLoS ONE, 8(5). https://doi.org/10.1371/journal.pone.0062814

Pedler, B. E., Aluwihare, L. I., \& Azam, F. (2014). Single bacterial strain capable of significant contribution to carbon cycling in the surface ocean. Proceedings of the National Academy of Sciences of the United States of America, 111(20), 7202-7207. https://doi.org/10.1073/pnas.1401887111

Pruitt, K. M., \& Kamau, D. N. (1993). Mathematical models of bacterial growth, inhibition and death under combined stress conditions. Journal of Industrial Microbiology, 12(3-5), 221231. https://doi.org/10.1007/BF01584194

Ramanan, R., Kim, B. H., Cho, D. H., Oh, H. M., \& Kim, H. S. (2016). Algae-bacteria interactions: Evolution, ecology and emerging applications. Biotechnology Advances, 34(1), 14-29. https://doi.org/10.1016/j.biotechadv.2015.12.003

Ratzke, C., \& Gore, J. (2017). Modifying and reacting to the environmental pH drives bacterial interactions. Modifying and Reacting to the Environmental PH Can Drive Bacterial Interactions, 136838. https://doi.org/10.1101/136838

Rocap, G., Larimer, F. W., Lamerdin, J., Malfatti, S., Chain, P., Ahlgren, N. A., Arellano, A., Coleman, M., Hauser, L., Hess, W. R., Johnson, Z. I., Land, M., Lindell, D., Post, A. F., Regala, W., Shah, M., Shaw, S. L., Steglich, C., Sullivan, M. B., ... Chisholm, S. W. (2003). Genome divergence in two Prochlorococcus ecotypes reflects oceanic niche differentiation. Nature, 424(6952), 1042-1047. https://doi.org/10.1038/nature01947 
Roth-Rosenberg, D., Aharonovich, D., Luzzatto-Knaan, T., Vogts, A., Zoccarato, L., Eigemann, F., Nago, N., Grossart, H. P., Voss, M., \& Sher, D. (2020). Prochlorococcus cells rely on microbial interactions rather than on chlorotic resting stages to survive long-term nutrient starvation. MBio, 11(4), 1-13. https://doi.org/10.1128/mBio.01846-20

Saito, M. A., Mcllvin, M. R., Moran, D. M., Goepfert, T. J., DiTullio, G. R., Post, A. F., \& Lamborg, C. H. (2014). Multiple nutrient stresses at intersecting Pacific Ocean biomes detected by protein biomarkers. Science, 345(6201), 1173-1177. https://doi.org/10.1126/science. 1256450

Schriek, S., Rückert, C., Staiger, D., Pistorius, E. K., \& Michel, K. P. (2007). Bioinformatic evaluation of L-arginine catabolic pathways in 24 cyanobacteria and transcriptional analysis of genes encoding enzymes of L-arginine catabolism in the cyanobacterium Synechocystis sp. PCC 6803. BMC Genomics, 8, 1-28. https://doi.org/10.1186/1471-2164-8-437

Segev, E., Wyche, T. P., Kim, K. H., Petersen, J., Ellebrandt, C., Vlamakis, H., Barteneva, N., Paulson, J. N., Chai, L., Clardy, J., \& Kolter, R. (2016). Dynamic metabolic exchange governs a marine algal-bacterial interaction. ELife, 5(NOVEMBER2016), 1-28. https://doi.org/10.7554/eLife.17473

Seyedsayamdost, M. R., Case, R. J., Kolter, R., \& Clardy, J. (2011). The Jekyll-and-Hyde chemistry of phaeobacter gallaeciensis. Nature Chemistry, 3(4), 331-335. https://doi.org/10.1038/nchem.1002

Seymour, J. R., Amin, S. A., Raina, J. B., \& Stocker, R. (2017). Zooming in on the phycosphere: The ecological interface for phytoplankton-bacteria relationships. Nature Microbiology, 2(May). https://doi.org/10.1038/nmicrobiol.2017.65

Sher, D., Thompson, J. W., Kashtan, N., Croal, L., \& Chisholm, S. W. (2011). Response of Prochlorococcus ecotypes to co-culture with diverse marine bacteria. ISME Journal, 5(7), 1125-1132. https://doi.org/10.1038/ismej.2011.1

Shoemaker, W. R., Jones, S. E., Muscarella, M. E., Behringer, M. G., Lehmkuhl, B. K., \& Lennon, J. T. (2021). Microbial population dynamics and evolutionary outcomes under extreme energy limitation. Proceedings of the National Academy of Sciences of the United States of America, 118(33), 1-8. https://doi.org/10.1073/pnas.2101691118

Steinchen, W., \& Bange, G. (2016). The magic dance of the alarmones (p)ppGpp. Molecular Microbiology, 101(4), 531-544. https://doi.org/10.1111/mmi.13412

Teeling, H., Fuchs, B. M., Becher, D., Klockow, C., Gardebrecht, A., Bennke, C. M., Kassabgy, M., Huang, S., Mann, A. J., Waldmann, J., Weber, M., Klindworth, A., Otto, A., Lange, J., Bernhardt, J., Reinsch, C., Hecker, M., Peplies, J., Bockelmann, F. D., ... Amann, R. (2012). Substrate-controlled succession of marine bacterioplankton populations induced by a phytoplankton bloom. Science, 336(6081), 608-611. https://doi.org/10.1126/science.1218344

Ting, C. S., Hsieh, C., Sundararaman, S., Mannella, C., \& Marko, M. (2007). Cryo-electron tomography reveals the comparative three-dimensional architecture of Prochlorococcus, a globally important marine cyanobacterium. Journal of Bacteriology, 189(12), 4485-4493. https://doi.org/10.1128/JB.01948-06 
Tolonen, A. C., Aach, J., Lindell, D., Johnson, Z. I., Rector, T., Steen, R., Church, G. M., \& Chisholm, S. W. (2006). Global gene expression of Prochlorococcus ecotypes in response to changes in nitrogen availability. Molecular Systems Biology, 2. https://doi.org/10.1038/msb4100087

Ustick, L. J., Larkin, A. A., Garcia, C. A., Garcia, N. S., Brock, M. L., Lee, J. A., Wiseman, N. A., Keith Moore, J., \& Martiny, A. C. (2021). Metagenomic analysis reveals global-scale patterns of ocean nutrient limitation. Science, 372(6539), 287-291. https://doi.org/10.1126/science.abe6301

Van Boekel, M. A. J. S. (2002). On the use of the Weibull model to describe thermal inactivation of microbial vegetative cells. International Journal of Food Microbiology, 74(1-2), 139-159. https://doi.org/10.1016/S0168-1605(01)00742-5

Vetsigian, K., Jajoo, R., \& Kishony, R. (2011). Structure and evolution of streptomyces interaction networks in soil and in silico. PLoS Biology, 9(10). https://doi.org/10.1371/journal.pbio.1001184

Warringer, J., Anevski, D., Liu, B., \& Blomberg, A. (2008). Chemogenetic fingerprinting by analysis of cellular growth dynamics. BMC Chemical Biology, 8, 1-10. https://doi.org/10.1186/1472-6769-8-3

Weisskopf, L., Schulz, S., \& Garbeva, P. (2021). Microbial volatile organic compounds in intrakingdom and inter-kingdom interactions. Nature Reviews Microbiology, 19(6), 391-404. https://doi.org/10.1038/s41579-020-00508-1

Yelton, A. P., Acinas, S. G., Sunagawa, S., Bork, P., Pedrós-Alió, C., \& Chisholm, S. W. (2016). Global genetic capacity for mixotrophy in marine picocyanobacteria. ISME Journal, 10(12), 2946-2957. https://doi.org/10.1038/ismej.2016.64

Zheng, Q., Wang, Y., Lu, J., Lin, W., Chen, F., \& Jiao, N. (2020). Metagenomic and metaproteomic insights into photoautotrophic and heterotrophic interactions in a Synechococcus culture. MBio, 11(1). https://doi.org/10.1128/mBio.03261-19

Zoccarato, L., Sher, D., Miki, T., Segrè, D., \& Grossart, H. P. (2020). Comparative whole-genome approach to identify traits underlying microbial interactions. BioRxiv, 1-53. https://doi.org/10.1101/2020.06.30.179929 